\title{
KAJIAN ESTETIKA PADA RUMAH ADAT ACEH BESAR TAMAN RATU SAFIATUDDIN
}

\author{
Niko Andeska ${ }^{1^{*}}$, Rahmawati $^{*}$ \\ Jurusan Seni Rupa dan Desain \\ Institut Seni Budaya Indonesia (ISBI) Aceh \\ Jl. Transmigrasi, Gampong Bukit Meusara, Kec. Kota Jantho, Kab. Aceh Besar, 23911 \\ Aceh. Indonesia \\ Email:nikoandeska@isbiaceh.ac.id,rahmawati@isbiaceh.ac.id
}

\begin{abstract}
Abstrak
Rumah adat di Indonesia memiliki ciri khas masing-masing dengan bentuk fisiknya yang beragam hingga estetik ornamen yang terukir di setiap bagiannya, salah satunya dapat kita lihat pada rumah adat Aceh. Rumah adat di provinsi Aceh disebut dengan Rumoh Aceh. Rumah adat yang identik dengan persegi empat memanjang dengan ukiran yang beragam. Salah satu keunikan rumah adat Aceh yaitu bentuk ukiran ornamen yang memiliki perbedaan pada setiap Kabupatennya, baik dari segi bentuk ornamen, penempatan dan makna yang terkandung pada ornamen tersebut. Bentuk rumah adat yang diteliti adalah rumah adat Aceh Besar yang terdapat di Taman Ratu Safiatuddin, Banda Aceh. Penelitian ini dilakukan karena minimnya referensi yang tersedia berkaitan dengan ukiran ornamen rumah adat Aceh Besar, sehingga menjadi daya tarik bagi penulis untuk melakukan penelitian ini. Metode yang digunakan dalam penelitian ini menggunakan metode kualitatif. Metode Kualitatif ini dilakukan dengan cara mengumpulkan informasi dengan penentuan objek dan topik, observasi, penentuan informan, wawancara, pengambilan data hingga analisis data yang terkait dengan ukiran ornamen yang terdapat pada rumah adat Aceh Besar. Tahap analisis data menggunakan kajian estetika sebagai teori pembedah dalam penelitian bentuk ukiran ornamen rumah adat Aceh Besar.
\end{abstract}

Kata Kunci: ornamen, rumah, adat, kajian estetika.

\begin{abstract}
Traditional houses in Indonesia have their own characteristics with various physical forms to the aesthetic of the ornaments engraved on each part, one of which we can see in the traditional house of Aceh. The traditional house in Aceh province is called Rumoh Aceh. The traditional house is identical to the elongated rectangle with various carvings. One of the uniqueness of Aceh's traditional house is the form of carved ornaments that have differences in each district, both in terms of the shape of the ornament, the placement and the meaning contained in the ornament. The form of the traditional house studied was the Aceh Besar traditional house located in Taman Ratu Safiatuddin, Banda Aceh. This research was conducted because of the lack of available references relating to the carving of traditional Aceh Besar house ornaments, so that it became an attraction for the author to conduct this research. The method used in this research uses qualitative methods. This qualitative method is carried out by collecting information by determining objects and topics, observation, determining informants, interviews, collecting data to analyzing data related to carving ornaments found in traditional houses of Aceh Besar. The data analysis stage uses aesthetic studies as a surgical theory in researching the form of carving ornaments of traditional houses of Aceh Besar.
\end{abstract}

Keywords: ornaments, traditional, house, aesthetic study.

\section{PENDAHULUAN}

Rumah adat Aceh Besar merupakan salah satu rumah adat yang terdapat di provinsi Aceh yang memiliki banyak kemenarikan. Sebagai salah satu bagian kebudayaan yang memiliki identitas, ukiran rumah adat Aceh Besar harus dijaga dan dilestarikan untuk generasi kedepan. Ukiran motif yang terdapat pada rumah adat Aceh Besar menjadi sebuah ciri khas dari rumah adat tersebut. Pada setiap bagian rumah adat
Aceh Besar dihiasi dengan ukiran-ukiran khas Aceh Besar.

Seiring dengan perkembangan zaman, fungsi ukiran rumah adat Aceh Besar yang terdapat di Taman Ratu safiatuddin kini telah beralih fungsi, hal tersebut dapat kita ketahui dengan kurangnya minat khalayak umum khususnya generasi penerus untuk mengetahui tujuan 
dari ukiran yang terdapat pada rumah adat Aceh Besar tersebut.

Sebagaimana diketahui, fungsi yang terdapat pada karya seni terdiri atas sebagai media ekspresi, sebagai Penyampaian pesan, dan sebagai benda pakai. Fungsi yang dimaksud sebagai media ekspresi yaitu sebuah karya seni yang diciptakan dengan tujuan menyampaikan gagasan-gagasan yang diaplikasikan melalui sebuah medium. Fungsi sebagai penyampaian pesan yaitu sebuah karya seni yang diciptakan yang ditujukan untuk menyampaikan gagasan kepada khalayak umum atau golongan tertentu. Fungsi sebagai benda pakai merupakan karya yang diciptakan untuk dapat digunakan sebagai memenuhi kebutuhan.

Sebagaimana menurut dharsono dalam bukunya yang berjudul seni rupa modern edisi revisi menyatakan keberadaan karya seni secara teoritis mempunyai tiga fungsi yaitu: fungsi personal, fungsi sosial, dan fungsi fisik (Kartika, 2016: 29).

Ukiran motif yang terdapat pada rumah adat Aceh Besar memiliki fungsi yang utuh, dimana ukiran motif tersebut merupakan hasil dari gagasan leluhur yang diekspresikannya sebagai penghias rumah pada masa itu, sekian itu ukiran motif tersebut juga memiliki makna yang di sampaikan kepada khalayak umum.

Andeska, N., dkk (2019: 353) menyatakan bahwasanya ragam hias Aceh dapat dikatakan sebagai karya seni rupa tradisional yang tidak hanya sebagai pengindah akan tetapi juga sebagai tuntunan bagi masyarakatnya.

Akan tetapi, saat ini ukiran motif yang terdapat di rumah adat Aceh Besar sudah banyak yang tidak mengetahui maksud dan tujuan bentuk motif tersebut, bahkan buku serta penelitian para akademisi tentang ukiran motif yang terdapat pada rumah adat Aceh Besar bisa dikatangan sangat minim dan sangat sulit untuk ditemukan. Hal tersebut berdampak pada referensi masyarakat umum dan akademisi untuk mengetahui tentang ukiran motif yang terdapat pada rumah adat Aceh Besar. Berdasarkan minimnya sumber referensi yang tersedia, menjadi daya tertarik peneliti untuk mengangkat ukiran rumah adat Aceh Besar sebagai objek kajian.

\section{KAJIAN TEORI}

Penelitian ini menggunakan sumber referensi yang relevan sebagai refesensi dan perbandingan agar memperkuat gagasan dan konsep dalam arikel. Sumber referensi yang dijadikan sebagai refensi yaitu yang berjudul: "Makna Motif Ragam Hias Pada Rumah
Gorga : Jurnal Seni Rupa

Volume 10 Nomor 01 Januari-Juni 2021

p-ISSN: 2301-5942 | e-ISSN: 2580-2380

Tradisional Aceh Di Museum Aceh", “Tangan-Tangan Trampil, Seni Kerajinan Aceh”.

Buku dengan judul "Kemilau Warisan Budaya Aceh" Tulisan H. Harun Keuchik Leumiek. Buku ini menjelaskan macam macam kerajinan aceh pada zaman dahulu yang dikoleksi dalam museum pribadinya yang menggambarkan kemajuan tingkat intelektual dan ilmu pengetahuan yang pernah berkembang di aceh pada abad-abad kemajuannya. Sedangkan pembahasan tentang ukiran motif tidak ada disinggung dalam buku ini. Sehingga dapat dikatakan bahwa sumber ini hanya berfokus kepada fungsi dan kegunaannya.

Artikel ilmiah dengan judul "Makna Motif Ragam Hias Pada Rumah Tradisional Aceh Di Museum Aceh" Tulisan Maulin (2019) artikel ini menjelaskan tentang bagaimana makna motif ragam hias pada bagian luar rumah tradisional Aceh di Museum Aceh. Sedangkan yang dikaji oleh penulis yaitu ornamen rumah adat Aceh Besar di Taman Ratu Safiatuddin. Sehingga sumber ini dapat menjadi perbandingan dengan penelitian yang dilaksanakan.

Buku dengan judul Tangan-Tangan Trampil, Seni Kerajinan Aceh" Tulisan Leigh (1989), buku ini menjelaskan bahwa Aceh merupakan wilayah pelayaran yang terkenal dan sering dilalui kapal-kapal dagang. Buku ini juga menjelaskan tentang sejarah dan bentuk benda-benda kerajinan serta ornamen yang terdapat di Aceh. Sedangkan pembahasan tentang ornamen pada rumah adat Aceh Besar di Taman Ratu Safiatuddin tidak ada, melainkan pada buku ini hanya menampilkan beberapa nama dan bentuk motif yang terdapat di Aceh pada umumnya.

Berdasarkan perbandingan beberapa referensi yang relevan dari kajian teori di atas dapat disimpulkan bahwa kajian yang lebih mengulas masalah ukiran motif rumah adat Aceh Besar belum ada. Pembahasan ukiran motif yang terdapat pada rumah adat Aceh Besar yang terdapat di Taman Ratu Safiatuddin belum banyak disentuh oleh para akademisi dan peneliti. Maka dari itu, penelitian ini dilakukan guna menganalisa ornamen yang terdapat pada rumah adat Aceh Besar di Taman Ratu Safiatuddin.

Rumah adat Aceh Besar yang terdapat di taman ratu safiatuddin merupakan duplikasi dari rumah adat Aceh Besar pada umumnya, rumah adat tersebut memiliki ragam hias ornamen khas Aceh Besar dengan motifmotif yang terdapat pada bagian rumah disusun sedemikian rupa untuk memberikan nilai estetis pada rumah adat Aceh Besar tersebut. Estetika merupakan 


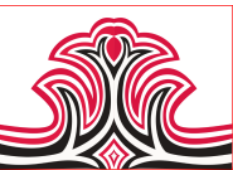

penggambaran dalam menginterpretasikan karya seni yang telah diciptakan oleh seniman atau pengkarya.

\section{METODE PENELITIAN}

\section{Rancangan Penelitian}

Penelitian yang berjudul, "Kajian Estetika Pada Rumah Adat Aceh Besar Di Taman Ratu Safiatuddin” ini akan melakukan penelitian dengan menggunakan pendekatan metode kualititatif. Metode Kualitatif ini dilakukan dengan cara mengumpulkan informasi dengan cara penentuan objek dan topik, observasi, penentuan informan, wawancara, pengambilan data sampai analisis data yang terkait dengan ukiran motif yang terdapat pada rumah adat Aceh Besar.

\section{HASIL DAN PEMBAHASAN}

\section{Hasil}

Berdasarkan observasi dan pengumpulan data yang telah dilakukan ragam hias yang terdapat pada rumah adat aceh besar memiliki bentuk yang berangkat dari bentuk tumbuhan sehingga mennjadi motif yang menhiasi rumah adat aceh besar yang di susun sedemikian rupa.

Pada rumah adat Aceh Besar pada bagian depan terdapat 8 bentuk motif yang di tempatkan, pada bagian belakang terdapat 7 bentuk motif, pada bagian samping kiri dan kanan terdapat 18 bentuk motif dan pada tangga terdapat 2 bentuk motif.

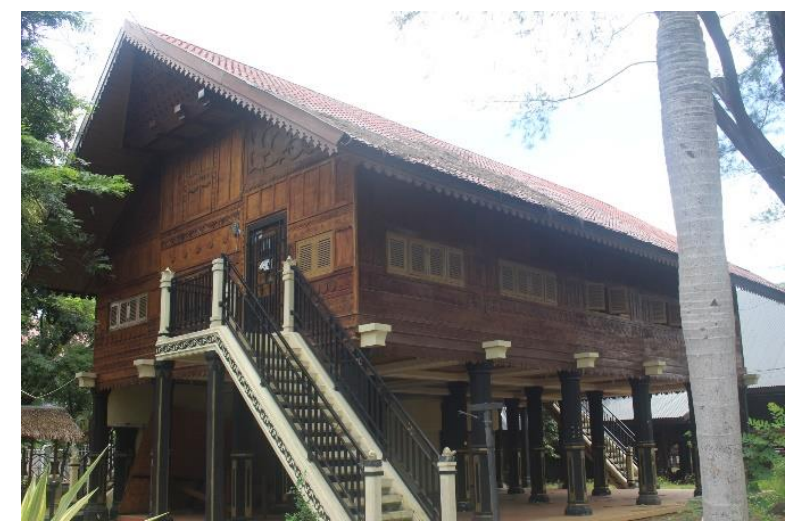

Gambar 1. Rumah Adat Aceh Besar di Taman Ratu Safiatuddin (Ghifari, 2020)

\section{Pembahasan}

Dalam menginterpretasikan ragam hias yang terdapat pada rumah adat aceh besar dapat dilakukan melalui prinsip tata susun yang terdapat dalam motif tersebut. Menurut Monroe konsep tata susun memiliki 3 ciri atau langkah untuk membuat suatu benda-benda estetis yaitu adanya kesatuan "unity", kerumitan "complexity" dan kesungguhan "intensity " (Kartika, 2016: 62).
Gorga : Jurnal Seni Rupa

Volume 10 Nomor 01 Januari-Juni 2021

p-ISSN: 2301-5942 | e-ISSN: 2580-2380

\section{1). Kesatuan "Unity"}

Suatu karya seni yang memiliki kesatuan "unity" jika karya tersebut terbentuk dengan baik dan memiliki kesempurnaan. Motif yang terdapat pada rumah adat aceh besar memiliki bentuk yang disusun sedemikian rupa hingga motif tersebut telihat sempurna disetiap sisi rumah adat aceh besar. Menentukan unity tidak lepas dengan tiga aspek penting, seperti apa yang telah disampaikan oleh Rofian (dalam Sitanggang, 2016: 172) menjelaskan bahwa dalam konsep pembelajaran khususnya seni rupa, ada tiga aspek yang dituangkan yakni kognitif (pengetahuan), afektif (sikap/apresiatif) dan psikomotorik (soft skills).

\section{2). Kerumitan "Complexity"}

Motif yang terdapat pada rumah adat aceh besar memiliki perbedaan-perbedaan yang halus seperti perbedaan antara 1 motif dengan motif yang lainnya.

\section{3). Kesungguhan "Intensity"}

Motif rumah adat aceh besar jika dilihat tidak hanya sekadar bentuk saja tetapi kaya akan isi dan makna sehingga setiap penempatanya memiliki maksud dan tujuan tertentu.

\section{KESIMPULAN DAN SARAN}

\section{Kesimpulan}

Rumah adat aceh besar sebagai salah satu objek yang dilestarikan terdapat di taman ratu safiatuddin memiliki berbagai macam bentuk ukiran motif yang ditempatkan pada setiap sisi rumah sehingga menjadi indah. Ukiran motif yang terdapat di dinding rumah adat aceh besar berjumlah 35 motif yang di tempatkan dan bentuk ukiran yang beragam. Secara keseluruhan motif ukiran tersebut diauaun san ditempatkan untuk membuat rumah adat aceh besar menjadi indah dengan memenuhi nilai - nilai kesatuan, kerumitan, dan kesungguhan. Rumah adat aceh besar di taman ratu safiatuddin tidak menggunakan pewarnaan seperti rumah adat lainnya, tetapi lebih menonjolkan natural sehingga meningkatkan nilai estetis yang terdapat pada rumah adat tersebut.

\section{Saran}

Berdasarkan penelitian yang telah dilakukan, peneliti berharap hasil penelitian ini nantinya dapat menjadi referensi dalam penelitian mauun informasi bagi akademisi dan masyarakat luas. Serta mendapat perhatian yang lebih untuk tetap melestarikan budaya dan tradisi aceh yang hampir terlupakan oleh masyarakat saat ini. 


\section{DAFTAR RUJUKAN}

Andeska, N., Setiawan, I., \& Wirandi, R. (2019). Inventarisasi Ragam Hias Aceh pada Iluminasi Mushaf AL-Quran Kuno Koleksi Pedir Museum di Banda Aceh. Gorga: Jurnal Seni Rupa, 8(2), 351-357.

Ghifari, Muhammad. (2020). "Foto Rumah Adat Aceh Besar”. Hasil Dokumentasi Pribadi: 2020, Taman Ratu Safiatuddin.

Kartika, Dharsono Sony. (2016). Kreasi Artistik: Perjumpaan Tradisi Modern dalam Paradikma Kekaryaan Seni. Karanganyar: Citra Sains.

Leigh, Barbara, (1989). Tangan-Tangan Trampi: Seni Kerajinan Aceh. Djambatan: Jakarta.

Maulin, S., Zuriana, C., \& Lindawati, L. (2019). Makna Motif Ragam Hias pada Rumah Tradisional Aceh di Museum Aceh. Jurnal Ilmiah Mahasiswa Pendidikan Seni, Drama, Tari \& Musik, 4(1), 78-96.

Paramita, N. C., Azmi, A., \& Azis, A. C. K. (2020). Upaya Meningkatkan Hasil Belajar Menggambar Bentuk Buah Teknik Krayon. Journal of Education, Humaniora and Social Sciences (JEHSS), 3(1), 171-177. 